\title{
Understanding Disability from a South Indian Perspective: A Case of Andhra Pradesh
}

\author{
*Prof. P. Arjun and B. Ganapathi ${ }^{1}$
}

\begin{abstract}
The purpose of this paper is to examine the disability understanding and perceptions towards physical people within the context of South India, drawing upon both secondary published sources, as well as interviews conducted with disabled people and their families in Andhra Pradesh. The paper compares and contrasts the experiences of disabled people in relation to the medical and social models of disability. Specifically, the paper will consider community attitudes encountered by disabled people and their families in both rural and urban areas; the relation between poverty, employment and disability; the issue of marriage and sexual relations of disabled people; and the apparent gender bias in the provision of community-based disability services in the South Indian context.

The principal findings of this research showed that the notion of "disablement" is both socially and culturally defined. What is considered a "disability" within a western society may not necessarily be the case in a society such as South India. For example, a person in South India who has dyslexia will find it comparative easy to obtain employment, where in a predominantly rural agrarian society, it is not a prerequisite to read to obtain work.

The conclusion is that people prepares to enter and people presently in the helping professions, but more importantly teachers of people studying to enter the helping professions, must be aware of the influence of their welfare schemes and religious perspectives and how to counter any negative effects which are to be found.
\end{abstract}

\section{Introduction:}

The purpose of this paper is to describe how "impairment and "disability" are encountered within a South Indian context, and what implications this has for the provision of disability services. It is impossible to provide a comprehensive analysis, since India is not only a country but a sub-content, with a population approaching one billion people. Therefore, the social, political and economic complexion of India is extremely diverse, particularly in terms of its class and caste composition and the diversity of religious faiths found within that country.

Between 5 and $10 \%$ of Indians have some impairment or disabling condition? This means that India has a huge population of disabled people. At the policy level, progressive legislation, schemes and provisions exist for them. But at the ground level, the disabled continue to be neglected and marginalised, with the onus of care on the family rather than the community. India needs to mark a shift from the medical model of intervention to community-based rehabilitation of the disabled.

\section{Understanding disability}

The concept of disability differs from society to society. Because attitudes towards disability are deeply rooted in socio-cultural values, the term 'disability' has been defined in many ways. Besides, other terms, such as 'impairment' and 'handicap' have been synonymously used for disability. The World Health Organisation (WHO) defines each term distinctly. Impairment is any loss or abnormality of psychological, physiological or anatomical structure or function.

Disability is any restriction or lack (resulting from an impairment) of ability to perform an activity in the manner or within the range considered normal for a human being. Handicap is a disadvantage for a given individual, resulting from an impairment or a disability, that limits or prevents the fulfilment of a role that is normal (depending on age, sex and social and cultural factors) for that individual.

The WHO definitions have often been criticised for focusing only on the individual and failing to reflect the extent to which the lives of disabled people are disadvantaged by the social structures of the society to which they belong. In a world in which there is increasing sensitivity to human rights and equality, one must view disability from a social perspective. The social model defines disability as the loss or limitation of opportunities to take part in the normal life of the community on an equal level with others due to physical and social barriers.

\footnotetext{
${ }^{1}$ Prof. P. Arjun Head of the Department, Social work and B. Ganapthi Research Scholar, Department of Social Work, Andhra University, Visakhapatnam
} 
According to the Persons with Disabilities (Equal Opportunities, Protection of Rights and Full Participation) Act, 1995, of the Government of India, a person with disability is a person suffering from not less than $40 \%$ of any disability as certified by a medical authority. The conditions included as disability are blindness, lowvision, hearing impairment, locomotor disability, mental retardation, leprosy and mental illness. Autism, cerebral palsy and multiple disabilities (eg mental retardation with blindness) have been listed as disabilities in the National Trust Act of 1999.

\section{Prevalence of disability}

No population-based study has been conducted at the national level to provide authentic data on the prevalence and incidence of disability in India. Therefore we must rely on the projections made by sample surveys.

According to the Project Integrated Education for the Disabled (PIED), under which a door-to-door survey was conducted in 1993 in a block each of ten selected states of India, nearly $2.5 \%$ of school-age children have disability of a given kind.

The National Sample Survey Organisation (NSSO 1991) estimated that approximately 100 million Indians are affected with one or more disabilities. This projected nearly $10 \%$ of Indians with some disabling condition. However, according to the Census 2001, approximately 5\% of people in India are affected with impairment or disability.

\section{Disability: Then and now}

Society values uniformity rather than diversity. Thus we tend to see ourselves as 'normal' or 'deficient'. The potential of homogeneity lies in the possibility of redefining society's concept of 'normalcy'. When people are given the right to belong, they are given the right to diversity.

India is an amalgam of cultures, religions, languages, philosophies and beliefs, customs and climates. But whoever they are, wherever they come from, whatever they do for a living, Indians value their diversity.

Despite their social, religious, economic, political and geographical differences, there are two characteristics that are shared by most Indians. One is tolerance and forbearance, and the other is an engrained belief in tradition and socio-cultural norms. These two characteristics have been responsible for the retention and maintenance of a social structure based on caste and class, and acceptance of injustice, discrimination, exploitation and abuse as part of one's karma or fate.

The status of disability and the course of the disability movement in India can be best understood within this framework. Ayurveda, a traditional Indian system of medicine, refers to disability, and provides guidelines for treatment. Particular mention has been made of mental retardation. Charaka and Susruta, famous ancient apothecaries, referred to mental retardation as 'manasmandyam' (weak head) caused by genetic, nutritional and environmental factors. But both of them maintained that these causative factors occurred as a result of 'Graha' (planetary influences). This line of thinking, in which the past, present and future are attributed to supernatural powers, typifies Indian philosophical thought with its belief in 'karma', and is accepted in large part even today. Indian history provides evidence that people with disability were either regarded as objects of pity or ridicule. Dwarfs and hunchbacks were often employed as jesters in the courts of Indian rulers. However demeaning, this royal patronage afforded the disabled some measure of social security. Systematic efforts for the treatment and education of the disabled began when Christian missionaries established homes for the rehabilitation of leprosy patients. The first artificial limb centre was set up during the Second World War. After independence India has introduced a variety of services and provisions for people with disability.

\section{Disability services and assistance: A review}

The rehabilitation of people with disabilities is the responsibility of the Ministry of Social Justice \& Empowerment. Services, assistance schemes and concessions are provided in collaboration with other ministries in the Government of India. The key areas where service initiatives have been taken are:

\section{Prevention, early identification and intervention}

Prevention, intervention and rehabilitation are part of a continuum. Prevention must be the priority of any government in order to reduce the incidence of disability.

The Integrated Child Development Services (ICDS) scheme was launched in 1975-76. Its objectives were to improve the nutritional and health status of children in the 0-6 age-group, provide nutrition and health education for all women within the age range of 15-44, and enhance the capability of mothers to tend to the health and nutritional needs of children.

The National Health Policy (1983) incorporated the WHO-sponsored Expanded Programme of Immunisation. The universal immunisation programme is a drive against diphtheria, pertussis, neonatal tetanus, tuberculosis, 
poliomyelitis and measles. The Pulse Polio programme has been undertaken nationwide for all Indian children (0-5 years) irrespective of their immunisation status. The target is complete eradication of polio.

The National Iodine Deficiency Disorder Control Programme of 1986 aimed to prevent occurrence of goitre, mental retardation and hearing impairment.

The Child Survival and Safe Motherhood Programme (1992) educates communities about pre-natal, peri-natal and post-natal care of the mother and infant in order to prevent infant mortality and developmental disabilities. The government has also set up a network of Primary Health Centres in the country.

Efforts for early identification of disability have been made both by government and non-government organisations (NGOs). Government hospitals are expected to have the expertise and equipment to screen and identify disability. Positive steps towards early identification of disability include the organisation of eye camps, and the involvement of anganwadi workers (nursery teachers in rural and urban poor areas), village communities and mass media. Appropriate screening and assessment tools have been developed.

Early intervention through infant stimulation, physiotherapy, occupational therapy, speech and language therapy, parent counselling and training, has been provided by many government hospitals and clinics run by NGOs. But these services are located in major cities and large towns only.

The role played by the National Institutes (autonomous bodies functioning under the Ministry of Social Justice \& Empowerment) is significant in prevention, detection and early intervention. The government has set up four National Institutes, one each for hearing impairment, visual impairment, locomotor disabilities and mental retardation. A fifth is being considered for multiple disabilities.

\section{Education, training and employment}

The education of children with disabilities is offered through a variety of service models ranging from segregation to full inclusion in a mainstream classroom.

There are more than 3,000 special schools in India today. Of them, 900 are schools for the hearing impaired, 400 for children with visual impairment, 700 for those with locomotor disabilities, and 1,000 for the intellectually disabled.

More than 50,000 children with disability are enrolled in the Integrated Education for Disabled Children, a government-sponsored programme. A few schools have resource rooms and employ special education teachers to help retain children with special needs in their system. Sadly, these facilities are found in very few cities.

Since there are almost no special schools or special educational services in rural India, integrated education for children with special needs is provided by default in the village schools.

Pre-vocational and vocational training is provided within the special educational centres. Besides this, training and rehabilitation education is also available at Vocational Rehabilitation Centres (VRC) in cities, District Rehabilitation Centres (DRC) for rural population in select areas and Regional Rehabilitation Centres (RRC) in four major cities of the country.

According to a government order a $3 \%$ reservation in jobs has been provided for the blind, deaf and physically impaired, in Grade $\mathrm{C}$ and D posts, so that each group avails a quota of $1 \%$ reservation. Certain jobs have been identified, and the decision made to post people with disabilities in jobs near their place of residence. Age and eligibility criteria may be waived to fit a person with disability in a given post.

\section{Legislative actions}

The last decade of the 20th century saw the enactment of three legislations for the rehabilitation and welfare of people with disabilities. The Persons with Disabilities (Equal Opportunities, Protection of Rights and Full Participation) Act was passed in 1995. This is an important legislation that provides for both preventive and promotional aspects of rehabilitation such as education, employment and vocational training, reservation, research and human resource development, creation of barrier-free environment, inclusion and independent living.

The Rehabilitation Council of India Act 1992 led to the establishment of the Rehabilitation Council of India (RCI). The RCI is responsible for standardising and monitoring training courses for rehabilitation professionals, granting recognition to institutions running courses, and maintaining a Central Rehabilitation Register of rehabilitation professionals. The RCI Act was amended in 2000 to give the RCI the additional responsibility of promoting research in rehabilitation and special education.

The National Trust Act 1999 provides for the constitution of a national body for the welfare of people with autism,cerebral palsy, mental retardation, and multiple disabilities. The Act mandates promotion of measures for the care and protection of persons with these disabilities in the event of the death of their parents, procedures for appointment of guardians and trustees for persons in need of such protection, and support to registered organisations to provide need-based services in times of crisis to the families of the disabled. The three legislations are comprehensive in spirit, and together deal with all aspects pertaining to rehabilitation, from 
prevention, training, employment, long-term settlement, human resource development and research and documentation.

\section{Concessions}

The Government of India offers special concessions to the disabled in the following areas:

Travel: The Ministry of Railways offers a discount of $75 \%$ on fare for all classes, and $50 \%$ on season tickets to a person with disability on production of a valid Certificate of Disability. Concession is also allowed for an escort accompanying a disabled person. Those with visual impairment and locomotor disability are eligible for $50 \%$ discount on airfare if they travel by Indian Airlines.

Communication: Blind literature and packages are exempt from postage and postal fees under prescribed conditions. Persons with visual and locomotor disability get preferential allotment for running STD/PCO telephone facilities.

Customs concessions: Import of special learning and mobility aids for personal use of persons with disability are exempt from customs duty.

Income tax concessions: The parent or guardian of a disabled person is entitled to a deduction up to Rs 40,000 in tax on income. Deduction is also permissible to an individual or family member with respect to expenditure incurred on medical treatment of a disabled person. The limit of this deduction is Rs 41,000. Deduction from total income of a disabled person has been raised to Rs 40,000.

Bank loans and subsidy: Persons with physical disabilities and institutions working for such persons can avail of loans from public sector banks at differential rates of interest. Under the Integrated Rural Development Programme, the physically disabled receive subsidy up to Rs 6,000 .

\section{Schemes}

The Government of India offers various schemes to encourage voluntary action for rehabilitation of the disabled. Through these schemes NGOs can access government support. Prominent among these schemes are provision for grants-in-aid to special schools, vocational training, employment, community-based rehabilitation projects, residential homes, and leisure and recreation centres etc. The NGO should be a registered society/public trust existing for at least two years prior to applying for financial aid.

\section{Implementing machinery}

Various agencies have been established to spearhead, maintain and encourage rehabilitation efforts. The National Institutes provide direct services (eg assessment, early intervention, training etc), conduct human resource development programmes, engage in research activities independently and in collaboration with voluntary agencies, and produce resource material and equipment relevant to Indian needs. Each National Institute has regional centres in different parts of India.

Under the provisions of the Persons with Disability Act (1995), the government has appointed a Chief Commissioner of Disabilities at the Centre, and a Commissioner of Disabilities in each state, who are responsible for implementing the Act. At the state level, the Ministry of Social Justice \& Empowerment implements its policies by funding and monitoring rehabilitation efforts of government and non-government agencies.

The University Grants Commission (UGC), the apex government funding agency for monitoring higher education, has sanctioned the setting up of Disability Units in universities to promote opportunities for higher education for persons with disabilities. Established under the UGC scheme of Higher Education for Persons with Special Needs (HEPSN), the Disability Units are expected to ensure that the physical and educational environments in affiliated colleges and departments of the university are conducive to students with disabilities pursuing higher education. Additionally, the Units would ensure that persons with visual, hearing and physical impairments are employed in the university under the $3 \%$ job reservation scheme.

\section{Disability: From paper to practice}

Whatever the provisions on paper, India's approach towards the rehabilitation of the disabled reflects the confused state of mind of a person who wants to be emancipated and modern while preserving age-old traditional values. Government policy, legislative actions, schemes and provisions for the disabled give the impression of a State that is committed to human rights and equal opportunities. But the ground reality is quite different. At the outset, not much has been done to create awareness about disability across the country. Most people continue to believe that disability is either an irremediable medical condition or an act of fate. In both cases the onus of care must rest with the family of the disabled and not on the community. Myths and misconceptions about disability abound, causing the disabled to be ostracised, isolated and marginalised. The legal definitions (Persons with Disability Act 1995) view disability strictly from the medical and/or 
psychometric perspective. This ends up reinforcing a medical model of intervention rather than the muchneeded community-based rehabilitation.

Prevention and early detection are important components of the medical model. However, measures taken for these are insufficient. While the Pulse Polio drive and immunisation against diphtheria, pertussis and tetanus have been quite successful, efforts for the prevention of other conditions such as blindness, deafness and neurological disabilities have been dismal. The incidence of developmental disabilities (eg mental retardation, autism) has increased to an alarming level.

Various schemes have been offered for the welfare of the disabled population, but lack of adequate information about them ensures that stakeholders -- disabled people, their families and organisations that work for them -- are either unaware or cannot avail of the provisions therein. At times the process of availing of the benefits of schemes is so cumbersome and time-consuming that most people prefer to by-pass them. Often, the government department selected for implementing a scheme is not notified of its details and their role in it. On the other hand, when the department concerned is notified, the officers assume a patronising attitude towards potential beneficiaries and delay the process of implementation. The Persons with Disability Act (PDA) promises creation of facilities in almost all areas pertaining to disability. But 'appropriate authorities' are directed to 'endeavour' or 'promote' integration (of persons with disabilities) 'within the limits of their economic capacity and development'.

Reactions to the provisions in the Act range from complete acceptance to total rejection. Those endorsing the Act do not feel the need to analyse its contents because they believe it is their efforts that finally culminated in legislation for the disabled. The critics of the PDA are concerned about the lack of an implementation mechanism. The Act does not override any existing laws. The positive rights are not fiscally supported. While clauses confer immunity to government authorities, parents and family members can be criminally charged for neglect and abuse.

Full inclusion of the disabled would mean removing the physical barriers of participation. Conditions and regulations that actually build physical barriers must be changed immediately. Thus rules for public buildings must be modified so that such buildings are accessible to persons with disabilities. The Motor Vehicles Act should make wheelchair accessibility an essential condition for manufacture of public transport vehicles.

Some people view the PDA as the government's effort to provide a legislative structure to what, in effect, is a statement of policy. But constitutional provisions without penal sanctions negate the advantage of enforcement, and make the usefulness of the legislative instrument questionable.

To the stakeholders in the field, disability legislation in India seems progressive in spirit but lacking in the strength to progress. On the other hand, a strong legislation might remove legal barriers to participation but cannot ensure removal of social barriers against people with disabilities. The use of powerful legislation has the advantage of creating an enforceable right, but the disadvantage is that the disabled may obtain inclusion without participation.

This brings us back to the social attitude towards disability. Most Indians view disability as matter of charity rather than a human rights issue. The charity perspective, while ensuring care and tolerance, promotes dependency among the disabled. The charity perspective also reinforces the belief that decisions regarding the nature, amount and recipient of charity should lie with the donor. On the other hand, the disabled and their families must accept their hardship with fortitude, as it is a part of their karma.

Though a lot must be done before such social beliefs change, the government can begin by removing disability rehabilitation from the auspices of the Ministry of Social Justice and Empowerment and placing it under the Ministry of Human Resource Development.

The need is to strengthen the disability movement and empower people with disabilities. In a country like India, it means that various departments of the government, such as education, health, transport, building works and employment, work in conjunction. It also means that the world's largest democracy must listen to the voice of people who have been on the margins, and bring them into the mainstream.

For organisations that work with the disabled, it means that they must abandon the agenda that promotes a specific disability or a group of disabled, and develop an advocacy programme that sensitises the community and the administration to the needs of people with disability as a whole.

\section{Further Reading}

[1]. Kohli A.S. (1997), Social Services to Disabled. Anmol Publications, New Delhi

[2]. Krishna, V.V., Dutt, B.S.V., Rao, K.H.(Ed) (2001), Disabled Persons. Discovery Publishing House.

[3]. Rao, A.P., Usha, M.N., (1995) Helping the Disabled: Indian Perspective. Ashish Publishing House. New Delhi.

[4]. Mishra, B, (1997) Integrating the Handicapped. Anmol Publications. New Delhi.

[5]. Information \& Guidance Booklet for Persons with Disabilities. Published by Rehabilitation Council of India, New Delhi

[6]. Kundu, C.L. (2000) Status of Disability in India 2000. Rehabilitation Council of India, New Delhi 